\title{
Protein- and RNA-synthesis independent bactericidal activity of ciprofloxacin that involves the A subunit of DNA gyrase
}

\author{
C. S. LEWIN, B. M. A. HOWARD* and J. T. SMITH*
}

Department of Bacteriology, University of Edinburgh Medical School, Treviot Place, Edinburgh EH8 9AG and "Microbiology Section, School of Pharmacy, University of London, 29-39 Brunswick Square, London WC1N

\begin{abstract}
Summary. Ciprofloxacin, unlike nalidixic acid, can kill Escherichia coli cells in the absence of synthesis of protein or RNA. Hence, chloramphenicol or rifampicin do not abolish the bactericidal activity of ciprofloxacin against wild-type $E$. coli. Protein and RNA synthesis were not required for the bactericidal activity of ciprofloxacin against nalB, nalC and nalD mutants of $E$. coli. However, the addition of chloramphenicol or rifampicin abolished the bactericidal activity of ciprofloxacin against a nalA mutant in nutrient broth. It is concluded that the ability of ciprofloxacin to kill $E$. coli in the absence of protein or RNA synthesis involves the A subunit of DNA gyrase.
\end{abstract}

\section{Introduction}

The 4-quinolones appear to act on DNA gyrase, the bacterial enzyme that introduces negative supercoils into DNA. ${ }^{1}$ Mutations affecting either the A or B subunits of this enzyme alter bacterial susceptibility to the 4-quinolones. ${ }^{2}$ Shen $e t$ al $^{3}$ have proposed that, rather than acting directly on DNA gyrase, the drugs bind to saturable sites on supercoiled DNA. This binding is suggested to be facilitated by DNA gyrase.

The molecular events leading to the death of bacteria exposed to the 4-quinolones are not known. However, differences have been observed amongst these drugs in the conditions required for their lethal action. Protein and RNA synthesis are essential for the bactericidal activity of the older 4-quinolones, such as nalidixic acid..$^{4,5}$ On the other hand, some fluoroquinolones kill bacteria in the absence of protein or RNA synthesis. ${ }^{6-9}$ This observation has led to the suggestion that these fluoroquinolones exert an extra bactericidal mechanism, termed $B$, in addition to that termed $A$, exhibited by nalidixic acid. Mechanism A requires protein and RNA synthesis as well as cell division ${ }^{4,5}$ but mechanism $B$, which is possessed by ciprofloxacin, ${ }^{6}$ DR-3355, ${ }^{7}$ fleroxacin, ${ }^{8}$ lomefloxacin, ${ }^{9}$ ofloxacin ${ }^{6}$ and pefloxacin ${ }^{8}$ does not require these activities, and allows the killing of non-dividing bacteria. The basis of mechanism B is unknown but has been suggested by Dalhoff ${ }^{10}$ to involve the bacterial membrane, rather than DNA gyrase.

In the present study, the bactericidal mechanisms of ciprofloxacin were determined for various mutants of E. coli KL16 that had altered susceptibility to 4quinolones. The aim was to determine whether mechanism $B$ could be abolished by specific mutations. Four different mutations were investigated: the nalA ( gyrA) mutation, which causes an alteration in the $\mathrm{A}$ subunit of DNA gyrase $;{ }^{11}$ the nalB mutation, which causes a reduction in permeability ${ }^{11}$ the nalC mutation, which alters the B subunit of DNA gyrase $;{ }^{12}$ and the nalD mutation, which appears to alter both the B subunit and permeability. ${ }^{13}$

\section{Materials and methods}

\section{Bacterial strains}

E. coli KL16, a prototroph, ${ }^{5}$ and its nalA,${ }^{11}$ nalB,${ }^{11}$ nalC (nal 31) $)^{12}$ and nalD (nal 24) ${ }^{13}$ mutants were used. All the mutants were resistant to nalidixic acid. The nalA, nalB and nalD mutations increased the MIC of ciprofloxacin, whereas the $\mathrm{nalC}$ mutation reduced the MIC of the drug (table). The strains were kept on nutrient-agar plates, which were subcultured every 10 days. Colonies taken from these plates were used to seed the overnight cultures for the experiments described below.

Table. MICs of ciprofloxacin for $E$. coli strain KL16 and mutants

\begin{tabular}{cc}
\hline $\begin{array}{c}E . \text { coli strain or } \\
\text { mutant }\end{array}$ & $\mathrm{MIC}(\mathrm{mg} / \mathrm{L})$ \\
\hline KL16 & 0.0075 \\
nalA & 0.05 \\
nalB & 0.01 \\
nalC & $<0.002$ \\
nalD & 0.02
\end{tabular}


a

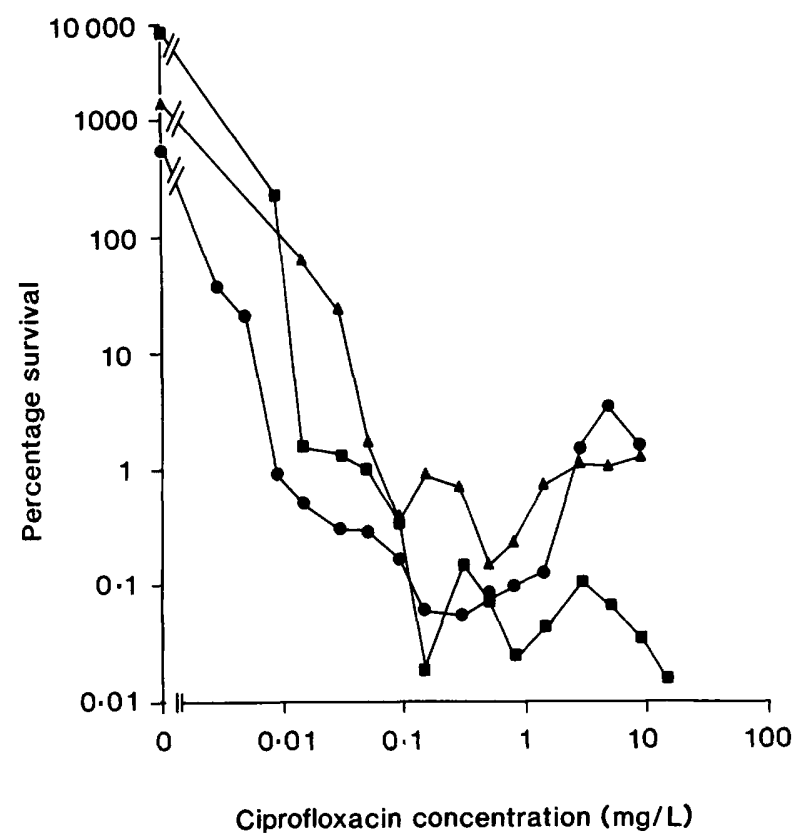

b

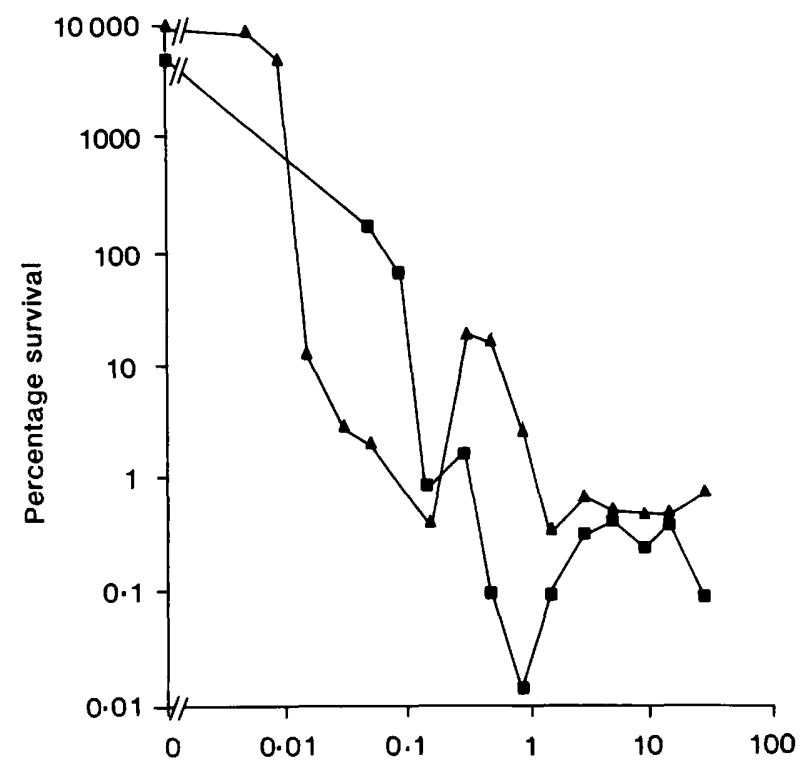

Ciprofloxacin concentration ( $\mathrm{mg} / \mathrm{L}$ )

Fig. 1. (a) Killing of E. coli KL16 - nalC $\square$ and nalD nutrient broth for $3 \mathrm{~h}$ at $37^{\circ} \mathrm{C}$. (b) Killing of $E$. coli nalA ciprofloxacin in nutrient broth for $3 \mathrm{~h}$ at $37^{\circ} \mathrm{C}$.

\section{Antibacterial preparation}

Ciprofloxacin (Bayer, UK) and chloramphenicol (Parke-Davis, UK) were dissolved in sterile distilled water. Ofloxacin (Hoechst UK) was dissolved in $0.5 \mathrm{M}$ $\mathrm{NaOH}(0.02 \mathrm{ml} / \mathrm{mg})$ before dilution in sterile distilled water. Rifampicin (Merrell Dow, UK) was dissolved in dimethylsulphoxide.

\section{Antibacterial activity of the 4-quinolones}

The bactericidal activity of ciprofloxacin (0.15-
$150 \mathrm{mg} / \mathrm{L}$ ) alone, or in combination with chloramphenicol, was determined in nutrient broth at $37^{\circ} \mathrm{C}$ after a 3-h exposure period. Bacteria were enumerated by serial dilution in nutrient broth followed by viable counting on nutrient agar, as described by Lewin $e t$ $a l .{ }^{14}$

The rate of kill of bacteria treated with ciprofloxacin and ofloxacin alone, or in combination with rifampicin, in nutrient broth was derived from sequential viable counts determined at 30 -min intervals over a 4-h period, as described by Lewin and Smith. ${ }^{15}$

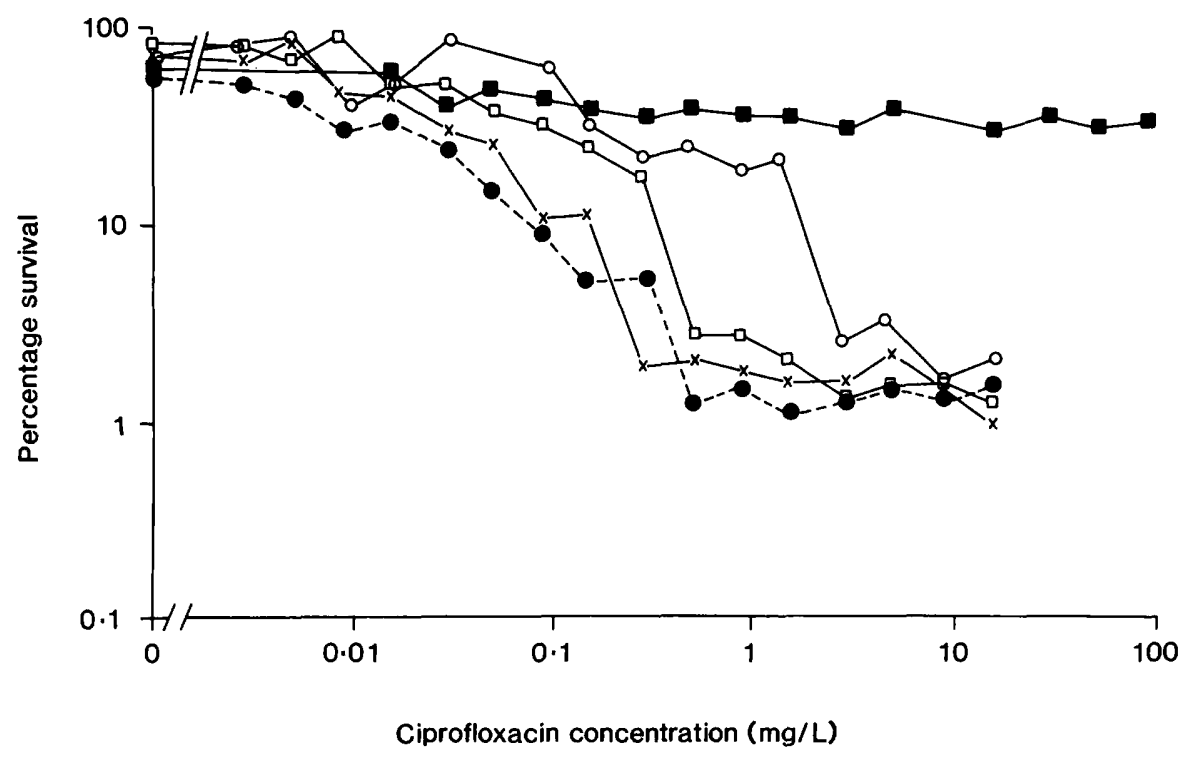

Fig. 2. Killing of E. coli $\mathrm{KL16} \longrightarrow \mathrm{-}$, nalA $\square-\square$, nalB $\square-\square$, nalC $\times-\times$ and nalD $\bigcirc-\bigcirc$ during exposure to various concentrations of ciprofloxacin in the presence of chloramphenicol $20 \mathrm{mg} / \mathrm{L}$ in nutrient broth for $3 \mathrm{~h}$ at $37^{\circ} \mathrm{C}$. 


\section{Results}

Ciprofloxacin, at concentrations above the MIC, was bactericidal against the nalA, nalB, nalC and nalD mutants (figs. $1 \mathrm{a}$ and $\mathrm{b}$ ). Addition of a bacteriostatic concentration of the protein-synthesis inhibitor chloramphenicol $20 \mathrm{mg} / \mathrm{L}$ reduced, but did not completely abolish, this activity against $E$. coli $\mathrm{KL16}$, and the nalB, nalC and nalD mutants (fig. 2). On the other hand, chloramphenicol $20 \mathrm{mg} / \mathrm{L}$ completely abolished the bactericidal activity of ciprofloxacin against the nalA mutant at concentrations up to $150 \mathrm{mg} / \mathrm{L}$ (fig. 2). Thus, ciprofloxacin was not bactericidal against the nalA mutant in the absence of protein synthesis.

The bactericidal activity of ciprofloxacin at its optimum bactericidal concentration (OBC, defined as the drug concentration giving the most rapid killing of the bacteria) was examined alone and in the presence of rifampicin, an inhibitor of RNA synthesis. At its $\mathrm{OBC}$, ciprofloxacin was bactericidal against the parent E. coli strains and the mutants (figs. 3-4). Addition of a bacteriostatic concentration of rifampicin $(160 \mathrm{mg} / \mathrm{L})$ reduced, but failed to abolish, the bactericidal activity of ciprofloxacin against the nalB, nalC and nalD mutants, confirming that the 4quinolone continued to exhibit mechanism $B$ against these organisms (fig. 4 and data not shown). However, addition of a bacteriostatic concentration of rifampicin completely abolished the bactericidal activity of ciprofloxacin against the nalA mutant (fig. 3).

The bactericidal activity of ofloxacin, which also exerts mechanism $B$, was investigated against the four mutants. Rifampicin abolished the bactericidal activity of ofloxacin at its $\mathrm{OBC}$ against the nalA mutant but

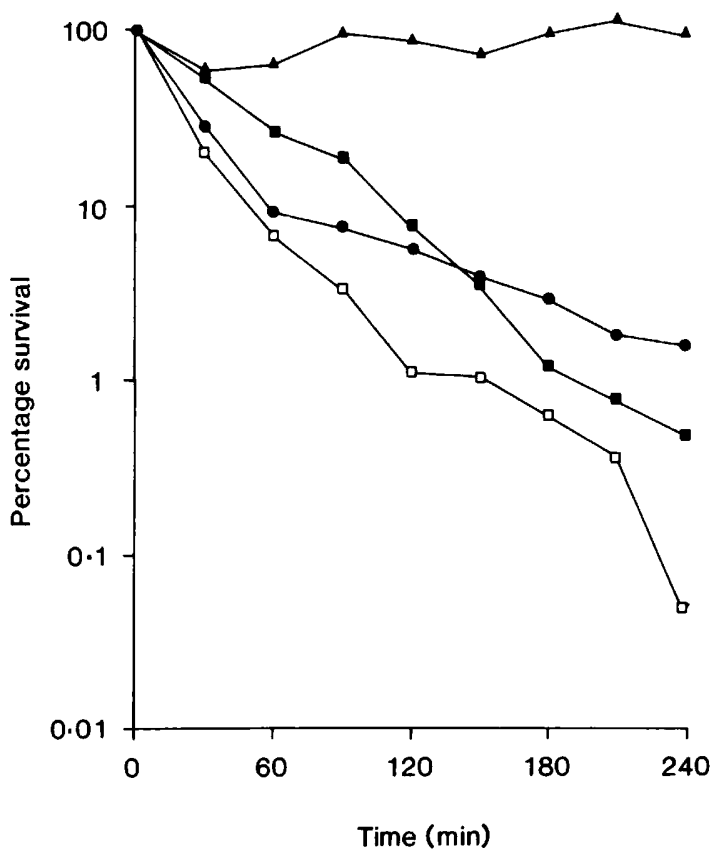

Fig. 3. Killing of $E$. coli KL16 during exposure to ciprofloxacin $0.15 \mathrm{mg} / \mathrm{L}$ alone $\square-\square$ and plus rifampicin $160 \mathrm{mg} / \mathrm{L}$ in nutrient broth at $37^{\circ} \mathrm{C}$, and of $E$. coli nalA during exposure to ciprofloxacin $0.9 \mathrm{mg} / \mathrm{L}$ alone and plus rifampicin $\Delta-\Delta$ in nutrient broth at $37^{\circ} \mathrm{C}$.

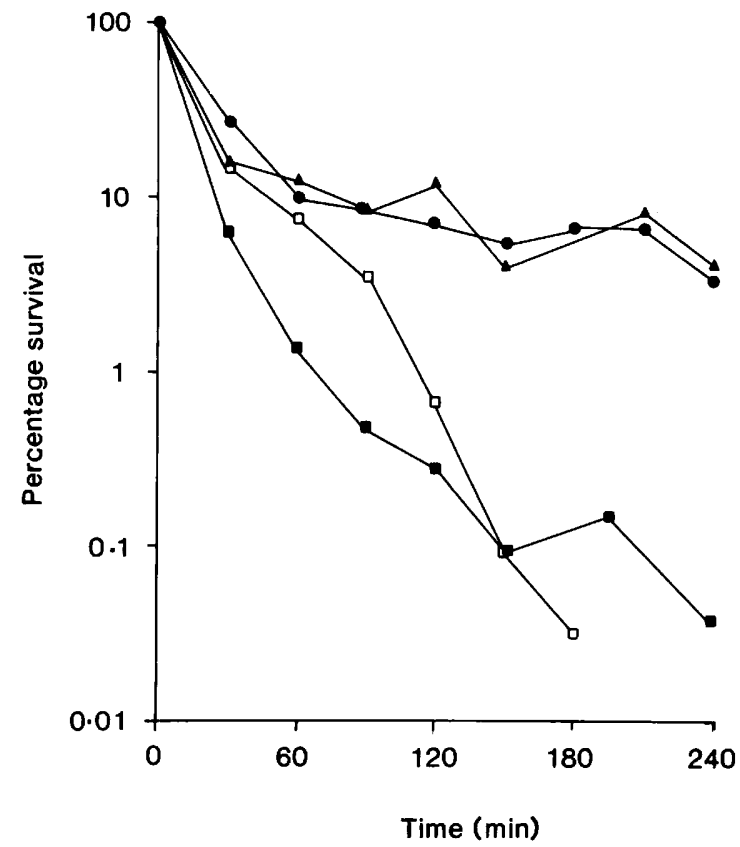

Fig. 4. Killing of $E$. coli KL16 during exposure to ciprofloxacin $0.15 \mathrm{mg} / \mathrm{L}$ alone $\square-\square$ and plus rifampicin $160 \mathrm{mg} / \mathrm{L} \Delta-\Delta$ and of the nalB mutant by ciprofloxacin $0.15 \mathrm{mg} / \mathrm{L}$ alone $\square-\square$ and plus rifampicin -0 . All experiments were performed at $37^{\circ} \mathrm{C}$ in nutrient broth.

not against the nalB, nalC or nalD mutants. Hence, as with ciprofloxacin, ofloxacin could not kill the nalA mutant in the absence of RNA synthesis.

\section{Discussion}

Protein and RNA synthesis were found to be prerequisites for the mechanism $B$-dependent bactericidal activity of ciprofloxacin or ofloxacin against a nalA $E$. coli mutant. Mutations which affected the outer membrane (nalB) or the B subunit of DNA gyrase (nalC and nalD) and which altered bacterial sensitivity to the fluoroquinolones had no effect on the occurrence of mechanism B. Thus, the fluoroquinolones were bactericidal against nalB, nalC and nalD mutants, even when protein or RNA synthesis were inhibited. These data suggest that mechanism $B$ involves the A subunit of DNA gyrase rather than the bacterial membrane, as has been suggested previously. ${ }^{10}$

It has been suggested ${ }^{16}$ that the possession of mechanism B explains why the frequencies of bacterial mutation to resistance to the fluorinated quinolones is much lower than to the non-fluorinated drugs such as nalixidic and oxolinic acids. ${ }^{2,16-19}$ It was proposed ${ }^{16}$ that two distinct mutations might be required to confer resistance to the fluoroquinolones whereas a single mutation would suffice for the older nonfluorinated drugs. However, the present data indicate that the nalA mutation abolishes mechanism B. In this context, it is interesting to note that although ofloxacin and ciprofloxacin both exhibit mechanisms A and B against $S$. marcescens, ${ }^{20}$ the frequency of mutation to resistance to the latter drug was higher than to the 
former. ${ }^{21,22}$ Hence, a low frequency of mutation resistance does not appear to be an inevitable correlate of possession of mechanism B by a drug. However, the possession of this additional bactericidal mechanism by the fluoroquinolones should still be advantageous as it enables these drugs to kill non-dividing bacteria. $^{6-9}$

Finally, we have recently reported that, in the absence of protein synthesis, ciprofloxacin is no longer able to kill $E$. coli strains that have acquired 4quinolone resistance during therapy. ${ }^{23}$ Thus, these isolates appear to have lost sensitivity to killing by mechanism B. ${ }^{23}$ As with the nalA mutant studied here, such isolates may have an alteration in the $\mathrm{A}$

\section{References}

1. Drlica K, Franco RJ. Inhibitors of DNA topoisomerases. Biochemistry 1988; 27: 2254-2259.

2. Lewin CS, Allen RA, Amyes SGB. Potential mechanisms of resistance to the modern fluorinated 4-quinolones. $\mathrm{J}$ Med Microbiol 1990; 31 : 153-161.

3. Shen LL, Mitscher LA, Sharma PN et al. Mechanism of inhibition of DNA gyrase by quinolone antibacterials: a cooperative drug-DNA binding model. Biochemistry 1989; 28: 3886-3894.

4. Dietz WH, Cook TM, Goss WA. Mechanism of action of nalidixic acid on Escherichia coli: III. Conditions required for lethality. J Bacteriol 1966; 91 : 768-773.

5. Smith JT. Awakening the slumbering potential of the 4quinolone antibacterials. Pharm J 1984; 233: 299-305.

6. Smith JT, Lewin CS. Chemistry and mechanisms of action of the quinolone antibacterials. In: Andriole VT (ed) The quinolones; London, Academic Press. 1988: 23-82.

7. Lewin CS, Amyes SGB. The bactericidal activity of DR-3355, an optically active isomer of ofloxacin. $J$ Med Microbiol $1989 ; 30: 227-231$

8. Lewin CS, Amyes SGB. Conditions required for the bactericidal activity of fleroxacin and pefloxacin against Escherichia coli KL16. J Med Microbiol 1990; 32: 83-86.

9. Lewin CS, Amyes SGB, Smith JT. Bactericidal activity of enoxacin and lomefloxacin against Escherichia coli KL16. Eur J Clin Microbiol Infect Dis 1989; 8: 731-733.

10. Dalhoff A. Interaction of aminoglycosides and ciprofloxacin with bacterial membranes. In: Adam $\mathrm{H}$, Hahn W, Opferkuch W (eds) The influence of antibiotics on the host-parasite relationship II. Springer-Verlag, Berlin and Heidelberg. 1985: 16-27.

11. Hane MW, Wood TH. Escherichia coli K-12 mutants resistant to nalidixic acid: genetic mapping and dominance studies. $J$ Bacteriol 1969; 99: 238-241

12. Yamagishi J, Yoshida H, Yamayoshi M, Nakamura S. Nalidixic acid-resistant mutations of the gyrB gene of Escherichia coli. Mol Gen Genet 1986; 204: 367-373. subunit of DNA gyrase. The loss of sensitivity to mechanism B-dependent killing might be exploited to identify gyrA (nalA) mutants. At present, although a high MIC for fluoroquinolones strongly suggests a gyrA phenotype, the only method of conclusively identifying the $g y r A$ gene as the site of mutation requires the purification of DNA gyrase. ${ }^{2}$ This is laborious and is not yet feasible for large numbers of isolates. The present results suggest that testing 4quinolone-resistant isolates for loss of mechanism B may provide a rapid screening method of identifying whether resistance could be due to a mutation in the gyrA gene. Further investigation with different strains will be required to confirm this proposal.

13. Hrebenda J, Heleszko $\mathrm{H}$, Brzostek K, Bielecki J. Mutation affecting resistance of Escherichia coli $\mathrm{K} 12$ to nalidixic acid. J Gen Microbiol 1985; 131 : 2285-2292

14. Lewin CS, Howard BMA, Ratcliffe NT, Smith JT. 4-quinolones and the SOS response. J Med Microbiol 1989; 29:139-144.

15. Lewin CS, Smith JT. Bactericidal mechanisms of ofloxacin. $J$ Antimicrob Chemother 1988; 22 Suppl C: 1-8.

16. Smith JT. Frequency and expression of mutational resistance to the 4-quinolone antibacterials. Scand J Infect Dis 1986; 49: Suppl: 115-123.

17. Barry AL, Gardiner RV, Packer R-R. Resistance to ten different fluoroquinolone antibiotics following in vitro exposures to nalidixic acid. Diagn Microbiol Infect Dis $1987 ; 6: 77-79$

18. Fernandes PB, Hanson CW, Stamm JM, Votjko C, Shipkowitz NL, St Martin E. The frequency of in-vitro resistance development to fluoroquinolones and the use of a murine pyelonephritis model to demonstrate selection of resistance in vivo. J Antimicrob Chemother 1987; 19:449-465.

19. Wolfson JS, Hooper DC. The fluoroquinolones: structures, mechanisms of action and resistance, and spectra of activity in vitro. Antimicrob Agents Chemother 1985; 28 . 581-586.

20. Lewin CS, Smith JT. Conditions required for the bactericidal activity of the 4-quinolones against Serratia marcescens. $J$ Med Microbiol (in press).

21. Watanabe $\mathbf{M}$, Inoue $\mathbf{M}$, Mitsuhashi S. In vitro activity of amifloxacin against outer membrane mutants of the family enterobacteriaceae and frequency of spontaneous resistance. Antimicrob Agents Chemother 1989; 33: 1837-1840.

22. Smith JT. In-vitro and in-vivo mutation frequencies to resistance-do they correlate in the long term? In: Crumplin GC (ed) The 4-quinolone antibacterial agents in vitro. Springer Verlag-Heidelberg. 1990: 215-227.

23. Lewin CS, Blakemore P, Drabu YJ, Smith JT. Loss of ciprofloxacin's second killing action in Escherichia coli that have developed 4-quinolone resistance during therapy. $J$ Antimicrob Chemother (in press) 